\title{
Teorias da Firma como Fundamento para Formulação de Teorias Contábeis
}

\section{Resumo}

Este artigo desenvolve ensaio acerca da extensão conceitual derivada da teoria da Firma e seu relacionamento com teorias contábeis vigentes, sumarizando as principais correntes que buscam explicar a firma, procurando estabelecer relacionamento com mudanças de rumo no objeto e objetivo da contabilidade, expressos pela pesquisa contábil atual. Argumenta-se que o conceito vigente de "firma" acaba direcionando a lógica informacional arraigada à contabilidade, por meio das acepções absorvidas pela teoria Contábil. O fulcro das ponderações considera o objeto da teoria contábil (registro e divulgação de agregados econômicos) direcionado aos usuários da informação contábil. A discussão é subsidiada pelas abordagens da teoria Neoclássica da Firma, da teoria contratual da firma e da Nova Economia Institucional (NEI), com enfoques em custos de transação, direitos de propriedade e custos de mensuração. Conceitos de economia de empresas direcionam a lógica conceitual vigente à teoria Contábil, com o sentido precípuo de fornecer informações eficientes aos stakeholders. Observa-se que a teoria da Contabilidade tem seus pilares fincados na teoria neoclássica da firma; e que através da teoria Contratual da Firma, que discute o monitoramento de agentes e de contratos, ela ultrapassa a limitada visão de função do controle patrimonial (stewardship), ampliando o foco do fornecimento de informações, além da função restrita de accountability. E, por fim, que, embora nem todos os elementos da nova economia institucional sejam apreendidos pela teoria Contábil, a NEI detém elementos de suma importância à consolidação das teorias contábeis quanto à sua institucionalização.

Palavras-chave: Teoria da Contabilidade. Teoria Neoclássica da Firma. Teoria Contratual da Firma. Nova Economia Institucional. Informação Contábil.
José Glauber Cavalcante dos Santos

Bacharel em Ciências Contábeis (UFC) e Mestrando em Administração e Controladoria (UFC). Contato: Av. da Universidade, $n^{0} 2431$, Bairro Benfica, Fortaleza, Ceará, CEP: 60.020-180. E-mail: jglauber_cont@hotmail.com

\section{Thalita Silva Calíope}

Bacharel em Administração (UFC) e Mestrando em Administração e Controladoria (UFC). Contato: Av. da Universidade, $n^{\circ} 2431$, Bairro Benfica, Fortaleza, Ceará, CEP: 60.020-180. E-mail: thalitacaliope@gmail.com

\section{Antônio Carlos Coelho} Pós-doutorado em Ciências Contábeis (USP) e Professor Associado (UFC).

Contato: Av. da Universidade, $n^{0} 2431$, Bairro Benfica, Fortaleza, Ceará, CEP: $60.020-180$.

E-mail: accoelho47@gmail.com 


\section{Introdução}

A função precípua da Contabilidade se define, ao longo dos tempos, como o ato de coletar, registrar, acumular e reportar os fatos econômicos concernentes à operação de entidades econômicas, as firmas, principalmente, as quais, em conjunto, formam a essência da atividade econômica da sociedade.

Assim, entende-se tratar-se de prática social que possui suas bases fincadas na teoria Econômica. Sua utilidade, como ferramenta informacional, encontra-se intimamente associada à concepção de "firma" que, por sua vez, sofre influência do contexto histórico e teórico a que pertence. Tal construção demonstra-se pertinente na medida em que as pesquisas preocupadas em discutir como a informação da contabilidade interfere na tomada de decisão precisam, necessariamente, apoiar-se em arcabouço científico que explique essa relação implícita.

Um dos desafios da Contabilidade interpõe-se à maneira pela qual se provê ao usuário a informação contábil para o processo decisório. Primeiro, porque são amplos e diversos os grupos de interesse que buscam responder a uma questão comum: “Onde devo investir?" Segundo, que, para amparar tais stakeholders, a informação gerada deverá incorporar características tais como: materialidade, utilidade, oportunidade e relevância, de modo a ser eficiente, isto é, ser capaz de contribuir para alterar a decisão do usuário externo.

Por outro lado, devido à sua natureza prescritiva, subjetivamente coordena as ações decisórias de um amplo espectro de agentes (Branco, 2006). Vale destacar que há ramo da teoria contábil que segue claramente preceitos sociais que dizem respeito à atividade interna da firma, onde as decisões não são decorrentes de preço, mas de custos de transação (poder de fiat), também objeto de análise pela nova economia institucional (Williamson, 1985) e tratado como o veio da teoria Contábil que está condicionado a teorias sociais e institucionais (Iudícibus, 2013).

De outra parte, as pesquisas em economia de empresas têm evoluído na definição de "firma", cuja acepção se modifica ao longo do tempo, desde a definição neoclássica seminal de entidade que congrega fatores de produção para fabricação, comercialização e distribuição de bens e serviço (Penrose, 2006), passando pela ideia de "conjunto de contratos" e chegando aos estudos da Nova Economia Institucional (NEI), os quais discutem a natureza da firma.

O ensaio, então, sumariza as principais correntes que buscam explicar a firma, procurando estabelecer relacionamento com as mudanças de rumo no objeto e objetivo da Contabilidade, expressos pela pesquisa contábil atual. Argumenta-se que o conceito vigente de "firma" acaba direcionando a lógica informacional ora atribuída primordialmente à contabilidade, a partir de acepções que são absorvidas pela teoria Contábil, sem detrimento da visão ainda em discussão de sua vertente que acompanha também mudanças sociais.

Aspectos estruturais (ambiente externo e operacional), cognitivos (racionalidade limitada), comportamentais (oportunismo), informacionais (seleção adversa e risco moral), institucionais (ambiente jurídico e enforcement) e políticos (grupos de interesse, atividades de lobby e rivalidade entre empresas), para Caleman e Zylbersztajn (2013), são as dimensões que compõem o estudo de economia das empresas, portanto, influenciadores prováveis da direção da pesquisa e da atividade contábil.

\section{Teoria Neoclássica}

Mesmo tendo se aperfeiçoado, a teoria Neoclássica, segundo Tigre (2005), recebe críticas pelo fato de desconsiderar variáveis técnicas e organizacionais em favor de seus modelos de equilíbrio. Ocorre que, na teoria Neoclássica da Competição Perfeita, havia maior preocupação com o sistema de preços, a despeito da forma como as firmas se organizavam e competiam.

De acordo com Demsetz (1988), a teoria Neoclássica surge em meio ao debate que envolvia os mercantilistas e os defensores do livre mercado sobre qual seria o papel do estado na economia. Como destaca Tigre (2005), a concepção liberalista sustentava-se no fenômeno da "mão invisível", proposta pelo "pai da economia". Crowley e Sobel (2010) afirmam que, para Adam Smith, com a mão invisível, conseguia-se o alinhamento dos 
interesses individuais com a prosperidade da sociedade, se somente se, a "mão" operasse livremente. Em outras palavras, a partir do princípio da mão invisível se requer a descentralização, em detrimento do comando e do controle pelos gestores da firma - evidência de crítica à construção teórica da acepção de firma clássica.

Para que a descentralização da tomada de decisão venha a gerar melhores resultados, é imprescindível a observância de duas questões basilares. Primeiro, deve haver uma estrutura de incentivos que alinhem o interesse individual àquele da empresa. Em segundo lugar, sabendo-se do consumo das receitas da empresa pelos incentivos de alinhamento, deve-se frisar aos recebedores de incentivos que suas decisões em relação à firma têm um custo, suportado pela empresa (Crowley \& Sobel, 2010).

Depois de concebido o "perfil utópico" de firma clássica, demostravam-se intrínsecas à empresa algumas características específicas. Entre elas, se não aquela de maior relevância a este debate, a inexistência dos problemas de informação. Ora, considerando-se que todos os agentes relacionados à organização dispõem do mesmo conteúdo informacional, a busca por informação é, em sua totalidade, livre e sem custos adicionais (Lopes \& Martins, 2012). Não é à toa a inclusão do adjetivo que faz alusão ao idealismo ou ao fantasioso, visto que, obviamente, tal cenário foge significativamente à realidade.

Tigre (2005) lembra que a teoria Neoclássica, desenvolvida a partir do século XX, foi dominada pela concepção de firma tratada como agente individual. Atribuiu-se à firma o princípio de comportamento único (maximização do lucro), desconsiderando-se o princípio de utilidade dos agentes econômicos. Este status de firma equiparava-se ao de um consumidor individual, não sendo ela tratada como uma instituição. Nesse sentido, as variáveis que a firma manipula são determinadas pela estrutura de mercado, que acaba se impondo a ela.

Justamente no contexto descrito é que a Contabilidade encontra seu sentido. Essa mesma Contabilidade emerge como fruto de uma revolução do pensamento e uma necessidade iminente do indivíduo - ser dotado de racionalidade limitada.

Atribui-se o surgimento da Contabilidade ao movimento denominado renascimento, que, como produto deste, foi impulsionada pelas mesmas forças que fizeram renovar-se o espírito humano. A mudança do modo de pensar, nessa época, ocorria com a derrocada da visão teocêntrica e imediata ascensão do antropocentrismo, que trouxe à tona nova concepção do homem como principal agente edificador da história (Hendriksen \& Van Breda, 1999). Com base em Lopes e Martins (2012), a demanda do indivíduo está atrelada à utilidade econômica da contabilidade, que detém capacidade de modificar as crenças dos usuários da informação produzida acerca dos fluxos de caixa que serão gerados pelos ativos adquiridos no mercado. $\mathrm{O}$ distanciamento informacional existente entre a firma neoclássica e a corporação moderna explica como a Contabilidade surgiu e o seu papel na sociedade. De outra forma, depreende-se que:

A desconsideração da assimetria informacional enfraquecia muito a teoria clássica da firma. Sem a assimetria informacional não há utilidade para a própria contabilidade. (...) A teoria da firma sem problemas de informações não deixa espaços para a contabilidade e, dessa forma, prescrições sobre o comportamento da contabilidade baseadas nesse tipo de instrumental são bastante equivocadas (Lopes \& Martins, 2012, p. 32).

Iudícibus, Martins e Carvalho (2005) asseguram que o modo pelo qual a Contabilidade atinge o seu fim desenvolve-se por meio da expressão de suas três capacidades que a ela são inerentes: capturar o evento econômico que impacta a riqueza do indivíduo, precisar este fato e, em seguida, comunicar ao utilizador da contabilidade os efeitos daquele evento. Consubstancia-se assim sua natureza socioeconômica, calcada no espírito capitalista que se resumia na demanda pelo acompanhamento da evolução da riqueza patrimonial dos indivíduos e de suas entidades.

No entanto, Schumpeter (1961) compreende que o capitalismo é, em essência, forma ou método de transformar a economia, não se revestindo unicamente de caráter estacionário, pois isso seria impossível. Dentro dessa lógica, há de se convergir com o seguinte: “o impulso fundamental que põe e mantém em funcionamento a máquina capitalista procede dos novos bens de consumo, dos novos métodos de produção ou transporte, dos novos mercados e das novas formas de organização criadas pela empresa capitalista" (Schumpeter, 1961, p. 105). 
Sob esse prisma de análise, de fato, a Contabilidade transformou-se e transforma-se à medida que a conjuntura, não apenas econômica, mas social e política, também se modificam. Faz-se fundamental para ela, portanto, compreender os modelos de firma que emergem ao longo do contexto histórico, isso porque, com essas mudanças, o propósito da Contabilidade, sua funcionalidade e relevância no processo decisório ajustam-se às demandas informacionais que imperam.

Kam (1990) elucida que é possível apontar três razões (forças sociais) que culminaram com o desenvolvimento das entidades ou organizações. Inicialmente, o próprio espírito capitalista: motivação que inclina o indivíduo a buscar lucros para si - como destacaram Iudícibus et al. (2005), fortalecida essa tese nas ideias de Schumpeter (1961). Segundo, há eventos específicos, de cunho econômico e/ou político, que propiciam condições à resposta da entidade: determinismo ambiental/social. Por fim, as inovações tecnológicas, mencionadas também por Adam Smith, Pai da Economia, e Karl Max: tinham o poder de promover estímulo, não só à formação, mas também ao crescimento das organizações. Destarte, a Contabilidade nascia alicerçada pela preocupação com a riqueza criada pelas entidades, inclusive sua evolução. Este incômodo, intrínseco ao indivíduo racional, detinha em seu cerne fundamentação na teoria Econômica.

Conforme Tigre (1998) relata, a teoria Econômica objetiva a criação de modelagens que tenham capacidade de capturar a lógica existente no comportamento de firmas e do mercado. Dito isso, controvérsias sobre o real papel assumido pelas forças que influem no crescimento e na definição dos objetos da firma evidenciam que o esforço despendido pela teoria Econômica não surtiram efeito no tocante à criação de um quadro analítico convergente. Complementarmente, Bresser-Pereira (2009) mostra serem os sistemas econômicos o objetivo da economia. Na investigação de suas propriedades de distribuição, estabilidade e evolução, intenciona-se compreender e explicar esse tipo de sistema. Como consequência, os agentes econômicos se ajustariam a ele e seriam capazes de influenciá-lo. O autor preocupa-se ainda com o destaque das distinções entre as escolas Clássica e Neoclássica, sendo a principal delas a abordagem metodológica, pois:

A teoria econômica neoclássica geralmente se distingue da teoria econômica clássica pela substituição do valor da utilidade marginal ou de seu caráter "marginalista" pela teoria do valor-trabalho. Esse critério de classificação é válido, mas segundo a abordagem deste estudo, a distinção essencial é metodológica. A escola clássica utilizou principalmente o método histórico-dedutivo, enquanto a neoclássica, o método hipotético-dedutivo (Bresser-Pereira, 2009, p. 182).

O método hipotético-dedutivo permite a formulação de hipóteses precisas e quantificáveis, pois tem como princípio o homo economicus. Segundo essa premissa, o indivíduo possui comportamento totalmente previsível, agindo com oportunismo, a fim de garantir seus interesses individuais (Bresser-Pereira, 2009; Dias \& Machado, 2012). Esse raciocínio foi apropriado por diversos enfoques, citando-se Oliveira (2011), que discute acerca das escolhas do indivíduo quanto ao seu ingresso em uma atividade ilícita. Da maneira que comenta o autor, haverá, por parte do indivíduo, opção pela alternativa que lhe proporciona o maior retorno econômico.

Sustentando-se em princípios oriundos da teoria Econômica, a teoria Positiva da Contabilidade possui como autores seminais Watts e Zimmerman, entre outros. Nela impera um questionamento deveras pertinente: “Como é decidido, pela empresa, o tipo de informação a ser divulgado?". Para responder a essa questão, toma-se como premissa justamente a ação do indivíduo pela maximização do bem-estar pessoal. O interessante é que a firma passa a ser denominada aqui como um grupo de indivíduos. Porém, esses indivíduos possuem interesses pessoais. Sendo assim, na condição de vínculo com a empresa, a continuidade dela estreita-se à consecução dos objetivos do grupo (Dias \& Machado, 2012). Anteriormente, Crowley e Sobel (2010) foram lembrados quando mencionaram Adam Smith retratando o alinhamento de interesses ao descrever o fenômeno da mão invisível.

Coase (1978) denomina essa acepção como abordagem econômica do comportamento humano. O indivíduo irá confrontar suas escolhas com as suas necessidades, porque ele sabe que os recursos são escassos. Logo, ele sempre vai atuar de modo a beneficiar o seu interesse individual por ser ele um agen- 
te maximizador da sua satisfação. Facilmente se conclui que o método hipotético-dedutivo apresenta laços estreitos com o enfoque positivo da teoria da Contabilidade que, para Lopes e Iudícibus (2012), visa à descrição do desenvolvimento da Contabilidade no mundo real, procurando antever as ocorrências, chamado de poder preditivo.

Em direção distinta, o método histórico dedutivo da teoria Econômica não faz uso de pressupostos simplistas. Admite-se que a realidade, dotada de complexidade e em estado de constante mudança, carece de observação. Tanto aquele como este método têm caráter dedutivo, mas a atenção dada ao sequenciamento dos fatos observados e, principalmente, a manutenção da proximidade entre objeto de estudo e observador, durante todo o processo de dedução, distinguem os dois métodos (Bresser-Pereira, 2009).

À luz do que fora exposto por Dias \& Machado (2012), concorda-se que, a partir do método histórico, a Contabilidade é admitida como campo do conhecimento de natureza social. Isso quer dizer que, à medida que a sociedade modifica-se, a Contabilidade procura adequar-se as suas necessidades, cultura e organizações de certa época. Conclui-se que a sociedade influiencia a Contabilidade e vice-versa, constituindo-se então um mecanismo de dinamicidade.

Como a teoria Econômica nasce provida pela teoria Clássica, mas com seu elevado conteúdo histórico, fica evidenciado o fortalecimento da dualidade histórico-hipotética. Todavia, na vertente neoclássica, buscaram-se cada vez mais níveis crescentes de abstração, formalismo e emprego de modelos matemáticos, privando e desprovendo a economia de sua natureza eminentemente histórica. A abordagem neoclássica pretendeu a universalização de suas suposições em sentido transversal e longitudinal; deu-se prioridade, no entanto, ao estado estático e atemporal dos aspectos econômicos, esvaziando-se a vertente histórica da economia (Caballero, 2004).

Os reflexos da predominância do modelo hipotético sobre o histórico foi claramente sentido e absorvido pela contabilidade em seu processo de construção. Dessa forma, a teoria Neoclássica, com relação à firma e ao lucro, toma para si um conceito de lucro econômico utópico. Isso ocorre porque não há consideração dos fatores institucionais e comportamentais como endógenos à composição e obtenção do lucro. Por conseguinte, o debate acerca do monitoramento de contratos (teoria contratual da firma) e sobre o conflito permanente entre principal e agente (teoria da agência), que afetam a apropriação dos resultados da atividade econômica desempenhada pela firma, são postos à margem (Coelho, 2007).

Extrai-se de Caballero (2004) que a corrente dominante da teoria Econômica desenvolveu-se embasada pela teoria e método provenientes da economia Neoclássica. Sob este enfoque econômico, pressupõe-se o individualismo metodológico e o intercâmbio voluntário, com ênfase na eficiência. Em suma, as três estacas de sustentação da Ciência Econômica são a escolha racional, a estabilidade das preferências e o equilíbrio das interações. Em consequência desses vieses, a teoria econômica especializou-se no emprego dos modelos formais e nos métodos econométricos e estatísticos, adquirindo assim seu alto grau de rigor.

Segundo Vasconcelos e Cyrino (2000), o cerne da teoria Econômica Neoclássica baseia-se nas premissas do equilíbrio, certeza e racionalidade perfeita, resultando em uma análise imóvel do processo de tomada de decisão, com enfoque dado à maximização da função utilidade em período pontual, reconhecidos os processos tecnológicos e o preço de fatores e produtos. Nesse percurso, para Coelho (2007), a Contabilidade acabou herdando essa característica da teoria Neoclássica, visto que o lucro demonstrado por ela constitui-se, necessariamente, dessa endogeneidade. A qualidade informacional do lucro reproduz os conflitos envolvendo os diversos públicos que amparam a firma, isso porque cada tipo de stakeholder, em sentido amplo o usuário da informação gerada pela Contabilidade, age em função da maximização de sua utilidade.

Nesse sentido, infere-se que a relação entre economia neoclássica e o processo histórico da teoria Econômica é unidirecional e assimétrica. O imperialismo econômico neoclássico teve uma abordagem da história econômica em cima de um marco teórico estático supondo um mundo não institucional, sem custos de transação, dando-se pouca importância para os fatores de cunho cultural e político. O mercado e sua competitividade materializavam-se através do individualismo racional, com ímpeto guiado pelo egoísmo e pela maximização própria: as preferências são exógenas e estáveis (Caballero, 2004). 
Do exposto, depreende-se que a transitoriedade pela qual passa a Contabilidade, tendo de se adaptar às mudanças decorrentes do ambiente econômico cada vez mais globalizado e institucionalizado, faz-se importante para o aperfeiçoamento de seu objetivo principal, que é a geração de informação útil e oportuna ao tomador de decisão. As contingências alteram a contabilidade substancialmente e ignorá-las traz consequências importantes à qualidade da informação contábil. Não há custo de transação nulo e o individualismo puramente racional perde continuidade com a teoria Institucional, que menciona o indivíduo como agente que atua em função da maximização da sua utilidade, mas que toma para si determinadas ações pelo fato de estas serem consideradas legitimadas ante a sociedade, deixando-se o benefício em segundo plano. Mais além, abandona-se a ótica da organização como ser individual, que tem o administrador como figura idêntica ao proprietário, preconizada pela teoria Clássica. Com a teoria contratual da firma, amplia-se este escopo de análise.

\section{A Teoria Contratual da Firma}

O modelo de empresa que é descrito pela teoria clássica descreve a firma como possuidora de um proprietário-administrador. Assim, a mesma pessoa detém essas duas funções dentro da empresa, fornecer capital e administrar a organização. É dessa forma que se sedimenta a teoria da firma, sob uma concepção utópica de empresa, porque, sob esse arranjo, dois problemas comuns às organizações modernas inexistem: conflito de agência e assimetria informacional (Lopes, 2012).

Ambos, conflito de agência e a assimetria informacional, são temas centrais da teoria da Agência, capaz de fornecer base teórica à compreensão de processos organizacionais à luz da perspectiva principal-agente. Em linhas gerais, essa relação configura-se quando a tomada de decisão é realizada pelo agente em nome do principal (Subramaniam, 2006). A teoria da Agência, como se observa, rompe o paradigma do modelo de firma da teoria Clássica. Antes, discutir a emergência de conflitos entre administradores (agente) e proprietários (principal) era absurdo, porque estes eram a mesma pessoa. Com o advento da corporação moderna, no entanto, essa vertente da teoria Contratual da Firma defende serem diferentes os interesses, visto que há assimetria informacional (Rocha, Pereira, Bezerra, \& Nascimento, 2012).

De acordo com Rocha et al. (2012), é sabido que a informação contábil ocupa papel de destaque para a firma contemporânea. A problemática da assimetria informacional pode ser compreendida pelo fato de o agente, possuidor da informação útil à tomada de decisão, subsidiar o principal com informações incompletas. Mas, por que isso ocorre? E por qual motivo isso não era observado na firma clássica? No momento em que acontece segregação do controle da firma, antes inteiramente na mão do principal, passa o agente a levar em consideração, na tomada de decisão, os seus próprios interesses além daqueles da empresa.

Com o exposto, compreende-se que a concepção de firma trazida pela abordagem clássica esvazia as funções da Contabilidade, visto que não existe conflito de agência e não há assimetria de informações, pois a propriedade e a tomada de decisão são funções acumuladas de uma mesma pessoa. A existência da Contabilidade apoia-se na deficiência relativa à produção de informação, normalmente considerada imperfeita. Nesse contexto é que a teoria dos Contratos se aplica, tendo como pilar esses dois problemas (Lopes \& Martins, 2012).

Para a teoria Contratual da Firma, a empresa é considerada um conjunto de contratos que servem como intermédio entre os diversos agentes econômicos. Cada qual contribui com sua parcela no processo produtivo e, decorrente dessa contribuição, recebe algo em troca. Nessa relação, o agente é contratado pelo principal para realizar determinadas funções, aceitando remuneração por isso. Desta maneira, a contratação eficiente sugere alinhamento de interesses, redução dos conflitos de agência e, por conseguinte, diminuição do comportamento oportunista do administrador em detrimento dos interesses do acionista, lembram Machado, Silva, Moura, Benetti, Rocha e Bezerra (2012) 
Rezende, Facure e Dalmácio (2009) afirmam serem os contratos envolvendo stakeholders aquilo que fundamenta a firma. Esse raciocínio é coerente diante do argumento de que o problema dos custos de monitoramento e agência abarca todo o tipo de contratos, sejam eles entre empregados, fornecedores, consumidores e outros. Destarte, os pressupostos da teoria da Agência podem servir como arcabouço teórico importante na compreensão das relações contratuais. Vale ressaltar que, como defendem Vasconcelos e Cyrino (2000), nem a economia neoclássica, tampouco as abordagens contratuais da firma (teoria da Agência e economia dos custos de transação) trazem em seu cerne a discussão estratégica para o centro dos debates e preocupações da organização.

Fica claro que o problema de agência não se limita à dicotomia principal-agente. Além disso, preocupa-se a Contabilidade com a "permuta" do custo advindo do comportamento oportunista pelo oriundo dos instrumentos de monitoramento, questão abarcada pela governança corporativa. Em síntese, pelo custo de oportunidade, mitigar ou mesmo eliminar ações oportunistas é menos oneroso para a firma.

Pereira e Vilaschi (2006) comentam que a teoria Contratual da Firma pode ser caracterizada no contexto da governança corporativa. A governança corporativa compreende um conjunto de instrumentos que visa reduzir os conflitos de agência e alinhar os interesses entre principal e agente. Sendo, portanto, a empresa um conjunto de contratos que envolvem os diversos jogadores (players), o funcionamento adequado da firma depende, necessariamente, do equilíbrio contratual que fora estabelecido entre as partes. Deste ponto então se expõe o elo à governança corporativa, da teoria Contratual da Firma. O sistema jurídico de um país deve assegurar o cumprimento dos contratos (enforcement), ou seja, é a governança corporativa responsável pela elaboração de mecanismos capazes de alinhar interesses.

Aquino (2005) atenta que os contratos estabelecidos entre os agentes econômicos, que, como foi exposto, sustentam a firma, detêm custos inerentes a sua composição, portanto, é válido descrevê-los. São custos contratuais o custo de preparação dos contratos (search and information costs), os custos de conclusão dos contratos (bargaining and decision cost) e os custos decorrentes de monitoramento e de esforços de coerção para se que se façam cumprir as obrigações contratuais (supervision and enforcement costs).

Segundo Pereira, Bruni, Rocha, Lima e Faria (2010) uma diferença entre a firma da abordagem clássica e a firma percebida pela teoria dos Contratos é que, para esta última, a organização, composta pela soma dos contratos dos indivíduos ou jogadores, não possui mais o objetivo de maximização do lucro. Esse objetivo é convergido na maximização da utilidade dos detentores dos contratos, denominados estes de "direitos de propriedade". A metáfora dos contratos reflete o somatório de todos os indivíduos autointeressados na firma, que reconhecem que o bem-estar objetivado depende da competição com demais firmas. Assim, todos corroboram, mediante a entrega de algum recurso afim ao processo de produção da firma (trabalho, competências, capital, etc.).

Outra distinção feita, desta vez entre teoria Contratual e abordagem neoclássica, diz respeito ao surgimento do homem contratual (operador da organização) diferente do homo economicus e seu intuito maximizador. O surgimento do homem contratual estabelece-se por dois pressupostos comportamentais: cognitivo e emocional. O primeiro pressuposto referencia a racionalidade limitada, chamada de forma semiforte de racionalidade. Apesar de serem racionais, os agentes econômicos possuem limitação, pois, cognitivamente, há um déficit decorrente do processo de recebimento, estocagem, recuperação e processamento da informação. O outro pressuposto, o motivacional, é proveniente da orientação do indivíduo direcionada ao oportunismo. Assim, o agente econômico pode revelar a informação de maneira completa ou distorcida com o interesse de disfarçar, ofuscar, dissimular, distorcer ou confundir (Aquino, 2005).

De acordo com Mizumoto e Machado (2007, p. 6), a teoria da agência "propõe a visão contratual da firma, em que as partes são representadas pelo acionista com direito ao resíduo, tomador de risco e os demais stakeholders. Os problemas de governança são ex-post ao contrato, considerados contratos incompletos". Tal situação é exemplificada, pelos autores, da seguinte maneira: se os agentes podem deter conhecimento específico ao contexto gerencial, custoso ao principal, por outro lado, existe um conjunto de retornos da organização que está comprometido com o stakeholder. Além destes poderá haver outros retornos difíceis de serem identificados e mensurados. Estes são os direitos residuais, aos quais o agente ou os acionistas podem se apropriar. 
Outra implicação que emerge da teoria dos Contratos à Contabilidade é a existência do conservadorismo. Nas relações contratuais, os investidores podem vir a se sentir prejudicados por informações que englobam projeções de cenários otimistas fictícios e, neste ponto, deve ser eficaz a postura conservadora do agente. Com isso, passa a ser o conservadorismo complemento às condições de contratos entre os stakeholders, ajudando na redução dos custos de agência e na minimização dos conflitos que envolvem agentes e principais. Justificam ou explicam as práticas conservadoras da Contabilidade os contratos de remuneração (administradores), contratos de dívida, riscos relativos a ações litigiosas (investidores), tributação sobre o resultado, os processos de cunho político e regulatório (Dantas, Paulo, \& Medeiros, 2013).

Reforçando o alicerce teórico central da teoria Contratual da Firma, em que a organização é um conjunto de contratos, é inerente a demanda pelo equilíbrio das relações emergentes destes contratos, pois se necessita a proteção dos interesses dos agentes econômicos envolvidos. Os autores completam que a pertinência dada à informação gerada pela Contabilidade encontra-se neste cerne, pois é por meio dela que acontece o monitoramento dos contratos, compreendendo empresa e agentes econômicos. Em conclusão, deve-se expor que a eficiência das relações contratuais (e da firma) está diretamente relacionada ao acesso dos contratantes à informação contábil, bem como do intermédio feito a partir de mecanismos de governança (Dantas et al., 2013).

Cabe, como desfecho, por em destaque qual o papel da contabilidade no tocante à teoria Contratual da Firma. Segundo Lopes (2012), considerando-se a empresa um conjunto de contratos, é fundamental à Contabilidade, primariamente, corroborar gerencialmente com a harmonia do contrato entre firma $\mathrm{e}$ seus gestores. Por motivos já discutidos anteriormente, configurou-se um contexto no qual impera a assimetria informacional devido à separação da propriedade e do controle, comum à organização moderna. Em acréscimo, observa-se que o interesse do acionista distingue daqueles atrelados aos administradores, devido, entre outros motivos, ao direito residual (comprometimento antecipado). Por conta dos diversos grupos interessados, são também diferentes as demandas informacionais e a contabilidade deve ajustar-se nesse sentido. Da forma como conclui Demsetz (1988), uma teoria da Firma mais completa deve preocupar-se, preponderantemente, com o custo da informação.

Por meio da Nova Economia Institucional, outras questões são incorporadas à função-objetivo da firma que naturalmente interessam à Contabilidade. Na seção seguinte, são realizadas algumas colocações em torno dessas construções teóricas.

\section{A Nova Economia Institucional}

A Nova Economia Institucional (NEI) surge a partir da "evolução dialética tese-antítese-síntese" para aperfeiçoar a Teoria Neoclássica (Rocha, 2007, p. 7). Guerreiro (2006) explica que a nova economia institucional, embora se afaste da conjectura neoclássica da maximização da utilidade, não rompe com esta teoria, uma vez que se aproveita do ferramental neoclássico para explicar as instituições capitalistas. Na mesma linha, Branco (2006) e Aguilar e Silva (2010) evidenciam que, mesmo criticando a abordagem neoclássica, a nova economia institucional pode ser considerada como extensão desta, sendo baseada nos mesmos fundamentos metodológicos. Porém, Cardoso (2005) apresenta com uma das diferenças com a teoria neoclássica a existência de transações que têm um custo monetário - o custo de transação.

A Nova Economia Institucional surge em decorrência da obra de Coase (1937) "The Nature of the Firm", em que se tem a extrapolação do conceito de "firma", ao indicar que as firmas devem corresponder ao "mundo real". Além disso, tem-se a introdução dos custos de transação. De acordo com Santos (2007), a firma torna-se mais que uma função de produção, em que entram insumos e saem produtos, e passa a exercer a função de coordenação dos agentes econômicos, incorrendo em custos devido à coleta e ao processamento das informações e transformando-as em contratos que representam as transações. Caballero (2004) afirma que o marco teórico da Nova Economia Institucional concilia a visão "Coaseana" de custos de transação com a noção "Northiana" de instituições, em que as instituições são um meio para reduzir os custos de transação e alcançar maior eficiência. 
Assim, a principal suposição da Nova Economia Institucional é de que as instituições formam-se a partir de contratos entre indivíduos e grupos de indivíduos para minimizar os custos de transação. Coase (1960) explica, a partir da critica a tradição "Pigouviana", que não se devem eliminar os custos de transação, mas sim utilizá-los como meio para maximizar os ganhos. Bueno (2004) expõe, com base no trabalho de Coase, que, se não existissem os custos de transações, as instituições não seriam necessárias para explicar o nível de eficiência com que a economia opera.

A finalidade basilar da nova economia institucional é explorar o custo das transações, instigando meios alternativos de organização da produção (governança), inserido em uma estrutura analítica institucional. Destarte, a unidade de análise é a transação, operação onde são negociados os direitos de propriedade (Zylbersztajn, 1995). Ressalta-se que os custos de transação são inerentes a todas as firmas, inclusive ao governo, como Coase (1960, p. 12) explica: "O governo é uma super-firma (mas de um tipo muito especial), porque é capaz de interferir no uso dos fatores de produção por meio de decisões administrativas [...] Mas a máquina administrativa governamental não é em si sem custo".

Para Carlini e Dantas (2004), os custos de transação surgem quando as organizações, por não serem autossuficientes, interagem com os agentes que compõem as cadeias em que estão inseridos para, por exemplo, comprar insumos ou vender a produção. Williamson (1985), tratando da Economia de Custos de Transação (ECT), uma das vertentes da Nova Economia Institucional, aloca o problema da organização econômica como um problema de contratação, em que uma tarefa deve ser cumprida e para isso pode ser organizada por meio de várias alternativas. Contratos explícitos ou implícitos podem ser associados a tais alternativas. Porém, esses contratos incorrem em custos de transação, os quais o autor classifica em ex-ante ou ex-post.

Os custos ex-ante acontecem antes de a transação ser efetivada; são custos envolvidos na elaboração contratual, na negociação das partes interessadas e na prevenção de danos devido ao contrato. Já os custos ex-post ocorrem durante a vigência do contrato. Quando este se encontra incompleto diante de uma nova situação não prevista anteriormente, são, conforme Carlini e Dantas (2004), os custos de renegociação entre as partes, de monitoramento do contrato para evitar ações oportunistas e de adaptação às mutações do ambiente ou para incluir ajustes sobre algo que não tenha sido previsto inicialmente.

As transações são o elemento principal da Nova Economia Institucional. Assim, os fatores que as definem podem ser divididos em relação às características dos agentes (racionalidade limitada e oportunismo) e aos atributos das transações (especificidades dos ativos, frequência, incerteza), os quais originam os custos de transação e são apresentados por Williamson (1985) ao dissertar sobre o "homem contratual".

Há três níveis de racionalidade: maximização ou racionalidade forte, racionalidade limitada ou racionalidade semiforte e racionalidade orgânica, processualista ou racionalidade fraca (Williamson, 1985).

A maximização ou racionalidade forte pressupõe que os indivíduos são capazes de assimilar e processar todas as informações disponíveis de modo a maximizar seus objetivos (Farina, Azevedo, \& Saes, 1997). Já, na racionalidade limitada, o agente econômico busca um comportamento otimizador e racional, mas não consegue devido à limitação na capacidade cognitiva de absorver e processar as informações, não podendo, deste modo, ser totalmente racional nas decisões (Nogueira, 2003). Zylbersztajn (1995, p. 17) explica que "o conceito de racionalidade limitada leva à compreensão da importância dos atributos ex-post, característicos das relações contratuais". Na racionalidade fraca ou orgânica, tem-se que a capacidade do indivíduo não é suficiente para conduzir a escolha de um quadro institucional com o objetivo de minimizar problemas contratuais ex-post (Vesco, 2008).

Williamson (1985) propõe três níveis de comportamento oportunista: oportunismo ou autointeresse forte; autointeresse simples ou sem oportunismo; obediência ou ausência de autointeresse. Segundo Vesco (2008), o oportunismo relaciona-se ao comportamento antiético dos agentes envolvidos na transação, podendo ser resultado da incompletude dos contratos, gerando perdas para uma das partes envolvidas. Para o autor, oportunismo ou autointeresse forte fundamenta-se no comportamento egocêntrico dos agentes e divide-se a partir de uma visão temporal. Senju e Gomes (2006) explicam que o oportunismo ex-ante, ou seleção adversa, acontece quando um agente, atuando em beneficio próprio, oculta informa- 
ções que seriam úteis à tomada de decisões dos outros agentes. Já o oportunismo ex-post, ou risco moral, ocorre quando um agente atua em seu interesse próprio, na casualidade de uma contingência não antecipada contratualmente.

Vesco (2008) esclarece que o autointeresse simples prevê que os contratos originais serão mantidos durante toda sua vigência. Dessa maneira, mesmo os indivíduos sendo movidos por motivações egoístas, eles sustentam e cumprem os contratos. Esse pressuposto é aceito pelo pensamento neoclássico, em que os agentes econômicos não adotam atitudes oportunistas no período de validade dos contratos, cumprindo os contratos até o seu término. A ausência de interesse implica que as ações do indivíduo não são dirigidas por ele, mas, sim, por alguma entidade externa que dita normas e regras que precisarão ser seguidas.

Consolida-se, na Nova Economia Institucional, o agente como um ser de racionalidade limitada e comportamento oportunista. A partir disso e dos custos de transação, Cardoso (2005) conclui que os contratos são imperfeitos, o que pode gerar novos comportamentos oportunistas, a indispensabilidade do monitoramento das atividades (regulação) e o acréscimo de outros custos de transação. Soma-se a isso o fato de que as agências reguladoras, que são compostas por seres humanos, são afetadas pelas características descritas anteriormente, uma vez que tais membros das agências podem assumir comportamentos oportunidades e têm racionalidade limitada, e que o governo age em prol de seus stakeholders.

Fagundes (1997) ressalta que, na presença de assimetria de informações, surge a possibilidade de que a parte detentora da informação privilegiada comporte-se de maneira oportunista; a isso se denomina risco moral. $\mathrm{O}$ autor supracitado ressalta que outro problema associado à assimetria informacional é o oportunismo pré-contratual, o qual surge em decorrência da detenção de informação privada por parte de alguns agentes econômicos no momento anterior à decisão pela aceitação de um contrato, em que a outa parte tem interesse na informação, o que se qualifica como seleção adversa. Em um cenário de assimetria informacional, os custos de transação têm maior relevância, juntamente com o oportunismo e com a racionalidade limitada dos agentes, nesse sentido, Cardoso (2005) conclui que os contratos são incompletos.

Ainda relacionado ao comportamento dos agentes, Carlini e Dantas (2004) relatam que, quando esse relacionamento solidifica-se com base da confiança entre as partes, ocorre a construção da reputação, isto é, da percepção positiva da empresa no mercado devido às transações recorrentes. Isso é determinante para a redução dos custos de transação, pois, no instante em que as transações entre os agentes fortalecem-se, as partes envolvidas começam a confiar nas atitudes umas das outras, acarretando na minimização da incerteza.

Com relação às características das transações, Vesco (2008, p. 37) diz que "transações são realizadas entre os agentes econômicos, para trocar, permutar e comercializar bens, produtos, mercadorias e serviços". Bueno (2004) defende que tais custos concernem-se aos custos de possíveis quebras dos acordos constituídos para efetivar empreendimentos conjuntos, em condições de racionalidade limitada e de presença de comportamentos oportunistas.

Como há diferentes tipos de transações, o custo de cada uma depende de suas características. Williamson (1985, p. 68) explica que "a diversidade contratual é explicada, sobretudo, pelas diferenças básicas nos atributos das transações" e propõe os atributos fundamentais das transações: frequência, incerteza e especificidade dos ativos.

A frequência é o número de vezes que os agentes realizam as transações. Quanto maior a frequência com que os agentes se relacionam maior é o custo de se praticar uma ação oportunista, pois os ganhos esperados com as várias transações são maiores que o ganho esperado com a ação oportunista (Gonçalves, Alves, Rocha, \& Staduto, 2007).

A frequência das transações influencia tanto os custos da negociação, elaboração e monitoramento dos contratos, quanto o comportamento dos agentes em relação ao oportunismo e à construção de reputação (Nogueira, 2003). Desse modo, à proporção em que a frequência aumenta, principalmente entre os mesmos agentes, reduzem os custos dos contratos e os ganhos provenientes de ações oportunistas, pois elas podem descontinuar o relacionamento. Em contrapartida, o aumento da frequência aumenta os incentivos para a construção de reputação positiva pelos agentes. 
No que tange à incerteza, Fagundes (1997) explica que esta influencia as características das instituições, quando, em maior ou menor grau, a capacidade dos agentes antecipam os acontecimentos futuros, instigando a criação de formas contratuais mais flexíveis que regulem o relacionamento entre as partes envolvidas na transação. Essa flexibilidade é essencial em um contexto de incerteza, em que eventos não planejados podem gerar a necessidade de mecanismos que viabilizem o ajuste dos contratos.

A incerteza é a condição em que os agentes não conhecem os resultados futuros de uma transação e denota uma circunstância que difere da presença do risco, geralmente associado a uma distribuição de probabilidades conhecida de eventos previsíveis. Assim, quanto maiores forem as incertezas, maiores serão os custos de transação em virtude da crescente necessidade de cautela nos contratos, que limitam os retornos devido aos custos diretos ou da realização de investimentos inferiores aos essenciais para uma escala de produção ótima (Nogueira, 2003).

Segundo Williamson (1991), a especificidade dos ativos refere-se ao grau em que um ativo pode ser redistribuído para usos alternativos e por usuários alternativos sem o sacrifício do valor produtivo, havendo seis tipos de ativos específicos: (i) especificidade do local - quando as firmas localizam-se próximas umas das outras, economizando despesas de transporte; (ii) especificidade dos ativos físicos - são ativos cujo uso é específico, atendendo a uma demanda limitada; (iii) especificidade dos ativos humanos - são os investimentos em capacitação através de cursos, treinamentos, entre outros e surge a partir do "aprender fazendo"; (iv) especificidade da marca - referem-se aos investimentos na marca de um produto ou empresa; (v) especificidade de ativos dedicados - conjunto de investimentos para atender ao pedido de um determinado cliente; (vi) especificidade temporal - pode ser considerada como um tipo de especificidade local, em que a capacidade de resposta em tempo útil por ativos humanos no local é vital.

A especificidade dos ativos é o grau de perda de valor quando o recurso é eliminado da transação e aplicado em sua melhor utilização alternativa. Quanto maior a perda, maior a especificidade do ativo (Nogueira, 2003). Dessarte, quando um agente realiza investimentos em ativos específicos, outro agente envolvido na transação pode aspirar apropriar-se dessa quase-renda para aperfeiçoar suas condições na negociação, computando a perda a ser causada ao primeiro agente caso a transação não ocorra (Vesco, 2008). Conforme Zylbersztajn (1995), quando há ativos específicos nos contratos, surge a necessidade de compromissos temporalmente mais extensos, pelo menos o suficiente para reaver os investimentos cujo uso de oportunidade pode ser limitado.

De acordo Gonçalves et al. (2007), a nova economia institucional desenvolveu-se a partir de duas correntes, ambas baseadas nos custos das transações, porém com abordagens distintas. A primeira corrente tem como principal autor Oliver Williamson e explora o ambiente microinstitucional, analisando como as várias organizações (jogadores) reagem aos custos de transação, resultando nos níveis de eficiência. Já a segunda corrente, cujo principal expoente é Douglas North, compreende o ambiente macroinstitucional e a influência das instituições (regras do jogo) no resultado econômico das organizações.

Williamson (1991, p. 269) denomina a primeira corrente de Estruturas de Governança, sendo esta uma perspectiva microanalítica, que se concentra na eficácia comparativa com as alternativas genéricas para reduzir os custos de transação, abordando as estruturas de governança que regulam as transações que ocorrem entre as instituições; e a segunda de Ambiente Institucional, que representa "as regras institucionais do jogo", sendo estabelecidas as bases para a interação entre os agentes e a relação entre as instituições.

Carlini e Dantas (2004) explicam que os agentes econômicos, em consequência do oportunismo e da racionalidade limitada, desenvolvem estruturas de governança para minimizar os custos das transações, com o intuito de manter a perpetuidade dos contratos e afastar ações oportunistas, sendo que a estrutura mais adequada para a firma depende do nível de especificidade dos ativos envolvidos nas transações.

Para Maragno, Kalatzis e Paulillo (2006), a estrutura refere-se ao arcabouço institucional no qual a transação é realizada, ou seja, é o conjunto de instituições e tipos de agentes participantes das transações. Fagundes (1997) explica que o surgimento de instituições voltadas para a gestão e coordenação das transações decorre do objetivo, por parte dos agentes envolvidos, de reduzir os custos a estas associados. Assim, busca-se criar estruturas de governança apropriadas, entendidas como estruturas contratuais dentro 
da quais a transação é realizada: relações de compra e venda simples (mercado), organizações internas às firmas (hierarquias ou integração vertical) e formas mistas constituem exemplos de estruturas de gestão distintas (formas híbridas).

Em relação ao ambiente institucional, Nogueira (2003) dilucida que este surgiu da consideração de que esse elemento molda o comportamento dos agentes e os custos de transação. A partir da compreensão disto, as instituições tornam-se objeto de análise pela teoria. Segundo Maragno et al. (2006) o ambiente institucional é constituído por macroinstituições responsáveis pelas relações econômicas entre os agentes. Contudo, para que essas relações existam é imprescindível destacar três elementos: (i) regras formais - constituições, leis e contratos, por exemplo; (ii) restrições informais - são tradições, tabus, costumes, entre outros; e (iii) direitos de propriedade - direito do indivíduo de se apropriar de seu trabalho e dos bens que possui. De fato, deve-se concordar que "a propriedade, como expressão da individualidade humana, exerce papel fundamental em uma sociedade capitalista" (Aquino, 2005, p. 21).

Zylbersztajn (1995) assevera que a definição de bem preocupada demasiadamente com a descrição de suas características físicas e técnicas constitui-se um equívoco, devendo ela, necessariamente, englobar a delimitação dos direitos de propriedade relativos ao uso do bem. São os direitos de propriedade que determinam o valor do bem, porque, em geral, seu objetivo é impedir a sua utilização indiscriminada, ilimitada e incondicionalmente. Nesse sentido, é coerente concluir que as transações ou negociações ocorridas na sociedade nada mais são que a "materialização" da permuta de direitos de propriedade entre os indivíduos.

Zylbersztajn, Sztajn e Mueller (2005, p. 85) afirmam que o direito de propriedade "é como um feixe que engloba os direitos de uso, usufruto e abuso, e que confere o exercício da exclusão sobre a coisa, que permite afastar terceiros que dela pretendam se apropriar, usar ou gozar". Ainda segundo os autores, pelo conceito apresentado, a negociação não gira em torno do bem-objeto, mas sim quanto aos direitos de propriedade sobre as dimensões dos bens. Assim, a Nova Economia Institucional volta-se à lógica dos arranjos contratuais que embasam a criação dos direitos. A assimetria informacional impossibilita que os direitos de propriedade sejam negociados sem custo, pois haverá conflito. Desse modo, "os custos de transação são afetados pelo sistema legal e por normas não positivadas, que recaem sobre a alocação dos direitos de propriedade" (Zylbersztajn et al., 2005, p. 85).

Segundo Mueller (2005), para a economia neoclássica, há clareza na definição e perfeita segurança dos direitos de propriedade. Não há de se incorrer nenhum tipo de custo para obtenção e defesa de um direito de propriedade, porque eles são sempre respeitados. Ao contrário, a literatura que incorpora o debate sobre os direitos de propriedade, não importa se para a nova economia institucional ou para a análise econômica do direito, tem como objetivo o efeito causado pelos direitos de propriedade no comportamento dos agentes econômicos. Destarte, a sobreposição dos contratos e a formação da firma, gerando assim os direitos inerentes a cada agente econômico, teriam papel fundamental no seu modo de agir, levando-se em consideração a busca pela maximização da utilidade esperada.

Havendo custos de transação, são exigidos e devem ser empregados esforços no sentido de monitoramento e proteção, pois os direitos de propriedade não são delineados com perfeição, ou seja, o direito de propriedade é mantido e estabelecido pelo custo de transação (Aquino, 2005). As temáticas "controle, separação e expropriação" sustentam a ideologia capitalista do direito de propriedade. Na perspectiva comportamental de principal e agente, suportada por ideologia estrutural-funcionalista, os direitos de propriedade representam os valores a serem respeitados, e a ação do indivíduo baseia-se na razão da maximização da utilidade pessoal (Pinheiro, Carrieri, \& Joaquim, 2013).

Assim, como para a Contabilidade faz-se imprescindível a representação do fato econômico (transações), a fim de que seja alcançado o objetivo de gerar informação passível de utilização pelo usuário da informação contábil, reside aqui a contribuição do direito de propriedade, determinante na mensuração do valor dos bens e serviços negociados pelos diversos indivíduos e instituições. 


\section{Conclusões}

Como exposto, a Nova Economia Institucional, mesmo sendo construída como uma crítica à teoria Neoclássica, tornou-se extensão desta. Ao abordar a Contabilidade, percebe-se que esta tem seus pilares na teoria Neoclássica, a qual se baseia na racionalidade dos indivíduos, desconsiderando motivos que levam gestores (indivíduos) a optar por determinado comportamento (Guerreiro, 2006, Major \& Ribeiro, 2008). Nas conjeturas neoclássicas, a Contabilidade possui a capacidade para resolver qualquer problema relacionado à assimetria informacional, mas tal pressuposição pode ser falsa, uma vez que existe a possibilidade de distorção no gerenciamento da informação contábil (Cardoso, 2005).

Cardoso (2005) defende que, se no mercado o preço é o sistema de informação das características das transações, então a Contabilidade é o sistema de informação mais eficiente para determinar direitos de propriedade e para mensurar e recompensar a performance quando a atividade econômica é desenvolvida internamente à firma, isso porque o preço do mercado não está mais disponível nessa situação.

Infere-se que a Contabilidade não se apropria de todos os pressupostos e abordagens da Nova Economia Institucional, dada sua incompletude e imperfeição. Contudo alguns elementos são essenciais para esta ciência. Vale salientar que os principais preceitos desta vertente teórica econômica têm se direcionado para os relacionamentos internos à firma, tentando explicar como os agentes se relacionam sem incentivos de mercado, mas a partir de contratos relacionais. Neste aspecto, as teorias contábeis relativas a stewardship e accountability ainda são fortemente derivados de conceitos sociológicos, psicológicos e institucionais.

Por fim, a teoria Contratual da Firma delineia importante papel da prática contábil, qual seja o de permitir o monitoramento de contratos e de agentes, o que complementa e explica a opção informacional da Contabilidade, sobrepujando a função meramente de controle patrimonial. A máxima de que o papel preponderante da Contabilidade é de reduzir a assimetria informacional entre gestores e públicos de interesse (Cardoso, 2005) tem forte apoio conceitual na evolução das pesquisas em economia de empresas, ao buscar definir uma adequada teoria da Firma.

\section{Referências}

Aguilar, H. A., Filho, \& Silva, E. B., Filho. (2010). A crítica novo-institucionalista ao pensamento da Cepal: a dimensão institucional e o papel da ideologia no desenvolvimento econômico. Economia e Sociedade, 19(2), pp. 211-232. doi: http://dx.doi.org/10.1590/S0104-06182010000200001.

Aquino, A. C. B. (2005). Economia dos arranjos híbridos: o caso da coordenação de serviços em uma usina siderúrgica. Tese de Doutorado, Universidade de São Paulo, São Paulo, SP, Brasil.

Branco, M. C. (2006). Uma abordagem institucionalizada da contabilidade. Revista de Contabilidade \& Finanças, 17(42), pp. 104-112. doi: http//dx.doi.org/10.1590/S1519-70772006000300009.

Bresser-Pereira, L. C. (2009). Os dois métodos e o núcleo duro da teoria econômica. Revista de Economia Política, 29(2), pp. 163-190.

Bueno, N. P. (2004). Possíveis contribuições da nova economia institucional à pesquisa em

história econômica brasileira: uma releitura das três obras clássicas sobre o período colonial. Estudos Econômicos, 34(4), pp. 777-804.

Caballero, G. (2004). Instituiciones e historia económica: enfoques y teorías institucionales. Revisa de Economia Institucional, 6(10), pp. 135-157.

Caleman, S. M. Q., \& Zylbersztajn, D. (2013). Falhas organizacionais; tipologia, determinantes e proposta de modelo teórico. Organizações \& Sociedade, 20(65), pp. 261-282. 
Cardoso, R. L. (2005). Regulação econômica e escolhas de práticas contábeis: evidências no mercado de saúde suplementar brasileiro. Tese de Doutorado, Universidade de São Paulo, São Paulo, SP, Brasil.

Carlini R., Junior, \& Dantas, C. (2004). Análise contratual sob a ótica da economia dos custos de transação: a relação entre uma cooperativa hortícola e uma rede de supermercados no estado de Pernambuco. Revista de Administração Mackenzie, 5(2), pp. 105-122.

Coase, R. (1937). The nature of the firm. Economica, 4(16), pp. 386-405.

. (1960). The problem of social cost. The Journal of Law and Economics, 3, pp. 1-44.

(1978). Economics and contiguous disciplines. Journal of Legal Studies, 7(2), pp. 201-211.

Coelho, A. C. (2007). Qualidade informacional e conservadorismo nos resultados contábeis publicados no Brasil. Tese de Doutorado, Universidade de São Paulo, São Paulo, SP, Brasil.

Crowley, G. R., \& Sobel, R. S. (2010). Adam Smith: managerial insights from the father of economics. Journal of Management History, 16(4), pp. 504-508. doi: http://dx.doi.org/10.1108/17511341011073979.

Dantas, J. A., Paulo, E., \& Medeiros, O. R. (2013). Conservadorismo condicional na indústria bancária brasileira em situações de maior percepção de risco. Revista Universo Contábil, 9(2), pp. 83-103. doi: 10.4270/RUC.2013214.

Demsetz, H. (1988). The theory of the firm revisited. Journal of Law, Economics, \& Organization, 4(1), pp. 141-161.

Dias, J. M., Filho, \& Machado, L. H. B. (2012). Abordagens da pesquisa em contabilidade. In A. B. Lopes, \& S. Iudícibus (Orgs.). Teoria Avançada da Contabilidade. pp. 17-71. São Paulo. Atlas..

Fagundes, J. (1997). Economia Institucional: Custos de Transação e Impactos sobre Política de Defesa da Concorrência [Texto para Discussão, $\mathrm{N}^{\circ}$ 407], Universidade Federal do Rio Janeiro, Rio de Janeiro, RJ.

Farina, E. M., Azevedo, P. F., \& Saes, M. S. (1997). Competitividade: Mercado, Estado e Organizações. São Paulo: Ed. Singular.

Gonçalves C., Junior, Alves, Y., Rocha W., Jr., \& Staduto, J. (2007). A formação de redes horizontais à luz da Nova Economia Institucional: um estudo de caso. Anais do Encontro de Economia Paranaense, Curitiba, PR, Brasil, 5.

Guerreiro, R. (Ed.) (2006). A abordagem institucional na contabilidade gerencial. Revista de Contabilidade \& Finanças, 17(40), pp. 3-6. doi: http://dx.doi.org/10.1590/S1519-70772006000100001.

Hendriksen, E. S., \& Van Breda, M. F. (1999). Teoria da contabilidade. São Paulo: Atlas.

Iudícibus, S. (2013). Rumo à contabilidade econômica ou à nobre origem? Revista de Contabilidade \& Finanças, 24(61), pp. 1-10. doi: http://dx.doi.org/101590/S1519-70772013000100002.

Iudícibus, S., Martins, E., \& Carvalho, L. N. (2005). Contabilidade: aspectos relevantes da epopeia de sua evolução. Revista Contabilidade \& Finanças, 16(38), pp. 7-19. doi: http;//dx.doi.org/10.1590/S151970772005000200002 .

Kam, V. (1990). Accounting Theory. New York: John Wiley \& Sons.

Lopes, A. B. (2012). Teoria dos contratos, governança corporativa e contabilidade. In A. B.

Lopes, \& S. Iudícibus (Orgs.). Teoria Avançada da Contabilidade. São Paulo: Atlas. pp. 173-187.

Lopes, A. B., \& Martins, E. (2012). Teoria da contabilidade: uma nova abordagem. São Paulo: Atlas.

Machado, D. G., Silva, T. P., Moura, G. D., Benetti, J. E., Rocha, I., \& Bezerra, F. A. (2012). Informações no processo gerencial: um estudo das escolhas contábeis nas empresas de energia elétrica da BM\&FBovespa. Anais do Congresso Virtual Brasileiro de Administração, Distrito Federal, Brasília, Brasil, 9. 
Major, M. J., \& Ribeiro, J. (2008). A teoria institucional na investigação em Contabilidade. In: M. J. Major, \& R. Vieira (Org.). Contabilidade e controlo de gestão: teoria, metodologia e prática. (Cap. 2, pp. 37-59). Lisboa: Escolar Editora.

Maragno, R., Kalatzis, A., \& Paulillo, L. (2006, novembro). A nova economia institucional: aspectos que influenciam na relação comercial Brasil - União Europeia. Simpósio de Engenharia da Produção, Bauru, SP, Brasil, 8.

Mizumoto, F. M., \& Machado, C. P., Filho. (2007). Práticas de governança corporativa em empresa familiar de capital fechado: um estudo de caso. Revista de Negócios, 12(2), pp. 3-17. doi: http://dx.doi. org/10.7867/1980-4431.2007v12n2p03\%20-\%2017.

Mueller, B. (2005). Direitos de propriedade na nova economia das instituições e em direito e economia. In D. Zylbersztajn, \& R. Sztajn (Orgs.). Direito \& Economia. Rio de Janeiro: Campus.

Nogueira, A. (2003). Custos de transação e arranjos institucionais alternativos: uma análise da avicultura de corte no estado de são Paulo. Dissertação de Mestrado, Universidade de São Paulo, São Paulo, SP, Brasil.

Oliveira, A. A. G. (2011). Análise da eficácia do enforcement das obrigações de universalização dos serviços públicos de telecomunicações no Brasil. Dissertação de mestrado, Universidade de Brasília, Brasília, Distrito Federal, Brasil.

Penrose, E. (2006). A teoria do crescimento da firma. São Paulo: Editora da Unicamp.

Pereira, A. G., Bruni, A. L., Rocha, J. S., Lima, R. N., Filho, \& Faria, J. A. (2010). Teoria dos contratos, governança corporativa e auditoria: delineamentos para a discussão em teoria da contabilidade. Anais do Simpósio de Excelência em Gestão e Tecnologia, Resende, Rio de Janeiro, Brasil, 7.

Pereira, A. N., \& Vilaschi, A. (2006). Governança Corporativa e Contabilidade: explorando noções e conexões. Anais do Simpósio FUCAPE de Produção Científica, Espírito Santo, Vitória, Brasil, 4.

Pinheiro, A. S., Carrieri, A. P., \& Joaquim, N. F. (2013). Esquadrinhando a governança corporativa: o comportamento dos personagens sob o ponto de vista dos discursos dos autores acadêmicos. Revista Contabilidade \& Finanças, 24(63), pp. 231-242. doi: http://dx.doi.org/10.1590/S151970772013000300006 .

Resende, A. J., Facure, C. E. F., \& Dalmácio, F. Z. (2009). Práticas de governança corporativa em organizações sem fins lucrativos. Anais do Congresso USP de Controladoria e Contabilidade, São Paulo, São Paulo, Brasil, 9.

Rocha, W. (Ed.) (2007). Da contabilidade de custos à gestão estratégica de custos. Revista de Contabilidade \& Finanças, 18(43), pp. 3-8.

Rocha, I., Pereira, A. M., Bezerra, F. A., \& Nascimento, S. (2012). Análise da produção científica sobre teoria da agência e assimetria da informação. Revista de Gestão, 19(2), pp. 327-340. doi: http://dx.doi. org/10.5700/issn.2177-8736.rege.2012.49903.

Santos, S. (2007, novembro). A Nova Economia Institucional. Anais do Seminário Temático Centralidade e Fronteiras das Empresas no Século XXI, São Carlos SP, Brasil, 1.

Schumpeter, J. A. (1961). Capitalismo, socialismo e democracia. Rio de Janeiro: Fundo de Cultura.

Senju, E., \& Gomes, E. (2006). As novas formas de comercialização de energia: o caso dos leilões. Revista de Economia da UEG, 2(2), pp. 1-19.

Subramaniam, N. (2006). Agency theory and accounting research: an overview of some conceptual and empirical issues. In Z. Hoque (Org.). Methodological issues in accounting research: theories and methods. Londres: Spiramus. pp. 55-82. 
Tigre, P. B. (1998). Inovação e teorias da firma em três paradigmas. Revista de economia contemporânea, 2(1).

. (2005). Paradigmas tecnológicos e teorias econômicas da firma. Revista Brasileira de Inovação, 4(1), pp. 187-223.

Vasconcelos, F. C., \& Cyrino, A. B. (2000). Vantagem competitiva: os modelos teóricos atuais e a convergência entre estratégia e teoria organizacional. Revista de Administração de Empresas, 40(4), pp. 20-37.

Vesco, D. (2008). Impactos da alteração da gestão do governo estadual nos Indicadores contábeis das concessionárias de rodovias do Estado do Paraná de 1996 a 2006 - um estudo empírico. (Dissertação de Mestrado). Universidade Federal do Paraná, Curitiba, PR, Brasil.

Williamson, O. (1985). The economic institutions of capitalism: firms, markets, relational contracting. New York: Free Press.

. (1991). Comparative economic organization: the analysis of discrete structural alternatives. Administrative Science Quarterly, 36(2), pp. 269-296.

Zylbersztajn, D. (1995). Estruturas de governança e coordenação do agrobusiness: uma aplicação da nova economia das instituições. Tese de Livre Docência, Universidade de São Paulo, São Paulo, SP, Brasil.

Zylbersztajn, D., Sztajn, R., \& Mueller, B. (2005). Economia dos direitos de propriedade. In D. Zylbersztajn, \& R. Sztajn (Orgs.). Direito \& Economia. pp. 84-101.Rio de Janeiro: Campus. 